\title{
Survey of Students Regarding Zika Infection: Is the Next Generation Aware of the Dangers?
}

\author{
Joseph V. Pergolizzi ${ }^{1,2}$, Jo Ann Le Quang1, Robert Taylor ${ }^{1}$, Peter Magnusson ${ }^{3,4}$, \\ Megan Nalamachu' ${ }^{1}$, Claudio Pergolizzi' ${ }^{1}$, Virginia Bingol' ${ }^{1}$, Domenico Foti ${ }^{1}$, \\ Charles Wollmuth', Sumiyo Umeda-Raffa5, Robert B. Raffa ${ }^{2,6,7}$ \\ ${ }^{1}$ NEMA Research Group, Naples, Florida, USA \\ ${ }^{2}$ Neumentum Inc., Morristown, New Jersey, USA \\ ${ }^{3}$ Centre for Research and Development, Uppsala University, Uppsala, Sweden \\ ${ }^{4}$ Cardiology Research Unit, Institution of Medicine, Solna, Karolinska Institute, Solna, Sweden \\ ${ }^{5}$ Pharmaceutical Sciences (Form. faculty), Hokkaido University of Science, Hokkaido, Japan \\ ${ }^{6}$ School of Pharmacy, Temple University (Prof. em.), Philadelphia, Pennsylvania, USA \\ ${ }^{7}$ College of Pharmacy, University of Arizona (Adjunct prof.), Tucson, Arizona, USA \\ Email: robert.raffa@gmail.com
}

How to cite this paper: Pergolizzi, J.V., Quang, J.A.L., Taylor, R., Magnusson, P., Nalamachu, M., Pergolizzi, C., Bingol, V., Foti, D., Wollmuth, C., Umeda-Raffa, S. and Raffa, R.B. (2020) Survey of Students Regarding Zika Infection: Is the Next Generation Aware of the Dangers?. Pharmacology \& Pharmacy, 11, 306-315. https://doi.org/10.4236/pp.2020.1111025

Received: October 16, 2020

Accepted: November 16, 2020

Published: November 19, 2020

Copyright $\odot 2020$ by author(s) and Scientific Research Publishing Inc. This work is licensed under the Creative Commons Attribution International License (CC BY 4.0).

http://creativecommons.org/licenses/by/4.0/

\section{(c) (i) Open Access}

\begin{abstract}
In 2016 and 2017 an outbreak of the Zika virus in new locales shocked populations into awareness of the disease and of its imputed ability to cause serious fetal abnormalities, particularly microcephaly. There was a major reduction in travel by people of child-bearing age. But the temporary regression in the spread, and preoccupation with COVID-19, seem to have overshadowed concern about Zika virus. In order to investigate this phenomenon, we conducted an online survey of 157 high-school students from four schools in different parts of the United States regarding their knowledge, practices, and attitudes about Zika virus. The mean age of the respondents was $16.4 \pm 1.1$ years, $55 \%$ were girls, and $60 \%$ attended public (rather than private) schools. Most students (70\%) had taken no steps to prevent Zika, but said they would tell their parents or a physician if they were exposed. They relied primarily on school and the internet (76\% and $72 \%$, respectively) as trusted sources of information about the virus. The majority (73\%) said they would spend some time to learn more about Zika; girls exhibited more concern than did boys. Half (50\%) of respondents knew the signs and symptoms of Zika, but only $20 \%$ knew all the ways Zika could be transmitted and $31 \%$ why Zika prevention was crucial for pregnant women and their partners. The results of this study suggest that comprehensive national preventive healthcare educational programs are needed.
\end{abstract}




\section{Keywords}

Zika Virus, Microcephaly, Guillain-Barré Syndrome, Survey, High-School Students

\section{Introduction}

Zika is an arbovirus transmitted via a mosquito vector that was first identified in 1947. It is named after the site where it was first discovered, the Zika Forest in Uganda. Zika belongs to the genus Flavivirus of the family Flaviviridae [1] and was first isolated from a rhesus monkey source [2]. The first human case on record was identified in 1953 in a child in Uganda [3]. The virus spread to Central and South America, to Europe, India, Indonesia, Malaysia, Pakistan, the Philippines, Polynesia, Thailand, southern states in the United States, and Vietnam [1]. Although multiple modes of transmission are possible, including blood transfusion, sexual transmission, and mother-to-child transmission; in most cases, the virus is transmitted by mosquito bite [1]. In 2016 and 2017, widely publicized outbreaks of the Zika virus were reported in the United States [4]. In 2016, symptomatic Zika virus infections peaked at 5168 cases in the U.S. with more than 36,500 similar cases in U.S. territories [4].

The news reports of this unfamiliar new virus and its association with cases of fetal microcephaly (Figure 1) caused considerable fear and concern and it received extensive news coverage from April 2016 to March 2017. Many of these stories offered prophylactic recommendations such as avoiding travel $(77.6 \%)$ and using mosquito repellent (41.0\%) with most of these stories describing Zika outcomes $(78.8 \%)$ rather than symptomology (40.6\%) [5]. A social-media survey [6] of college students in 2016 reported a high level of awareness of the virus, but a study of Instagram users reported $60 \%$ of posts regarding Zika included incomplete, misleading, or unclear information about the virus [7].

Since there is no vaccine or effective treatment [8], it is imperative that people be aware of the almost-certain re-emergence of an outbreak and the steps necessary to avoid serious fetal abnormalities, such as microcephaly, that are associated with the virus. Unfortunately, COVID-19 has reduced reporting on Zika virus to almost zero. We therefore conducted an online survey among high school students in various schools in the United States. Some, but not all, of the schools were located in areas that might be directly affected by Zika. The aim of the study was to determine if students were aware of the Zika virus, how much it concerned them, and what precautions, if any, they know to take to avoid it. In light of the generational schism that emerged during COVID-19 where younger people seemed less concerned with infection than older people, it is perhaps noteworthy to find that in 2016, during the outbreak of a novel disease, we identify an important need for more effective and comprehensive educational programs. 


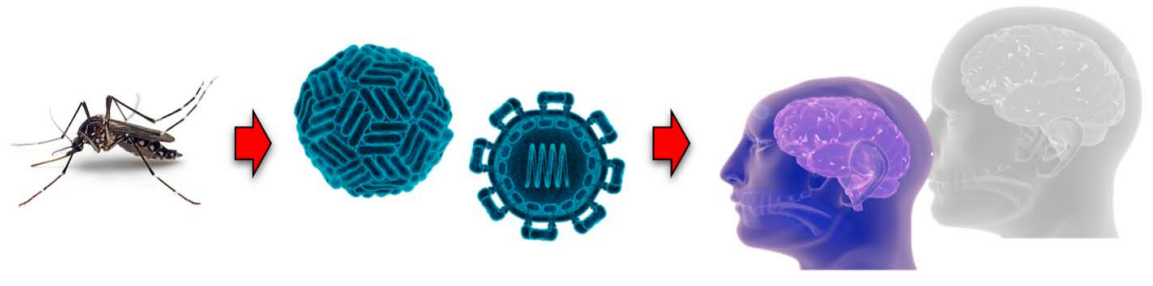

Figure 1. Zika virus is transmitted by mosquito (Aedes aegypti) bite and is associated with fetal defects such as microcephaly. Images purchased from iStock.

\section{Materials and Methods}

\subsection{Respondents and Procedure}

An online survey was used to assess the knowledge, attitudes, and practices regarding the Zika virus among 185 high school students distributed among highschools in distributed states in the U.S.A. (Florida, Illinois, Indiana, Kansas, Massachusetts, Missouri, New York, Pennsylvania, and Washington state). Students became eligible if: they provided electronic assent prior to answering any survey related question; were between the ages of 14 to 18 ; and attended either a public or private high school in the United States.

Prior to study initiation, an independent internal review board (IRB), Quorum IRB, reviewed and approved the study. The IRB approved a waiver of informed consent for the parent/guardian and a waiver of documentation of informed consent for the students.

Students took the survey online through a secure website (https://www.surveymonkey.com/) from May-June 2017. Each of the high schools had a student representative selected by the principal investigator to distribute the survey during school hours. Once distributed, students received an e-mail invitation to participate in the survey and were provided the survey information. The survey was accessible via any internet connection and could run on any web browser. Students were then required to provide their assent prior to answering any study questions, and any students who did not agree to assent were not able to access the survey. The survey was conducted anonymously, and no IP addresses were collected. Accessibility for the survey was provided for one month and each student was required to answer all questions on each page before moving onto the next page. However, the students were able to withdraw from the survey at any time without answering all the questions.

The survey was conducted to include questions about demographics, knowledge, information seeking, and the willingness to accept a vaccine. The main outcome of this study was to analyze the respondents' knowledge of Zika, and to see if there was any correlation to determine the willingness of the students to protect themselves against the virus. Knowledge of the study was assessed with 26 multiple choice questions, ranging from three to six possible answers per question in order to better understand the current attitudes these students have towards the Zika virus. In addition, two fill-ins the blank questions were also asked, informing the questionnaire of the age, and location of the student. 
The survey consisted of the following:

1) By clicking "I agree" below you are indicating that you are between the age of 14 and 18 years old, have read and understood this assent form and agree to participate in this research study. Please print a copy of this page for your records

2) How old are you

3) What is your sex $[\mathrm{M} / \mathrm{F}]$

4) Please select your race [multiple choice]

5) Please select your ethnicity [multiple choice]

6) In what state is your high school located

7) What grade level are you in

8) Is your high school a [public or private] school

9) What is the highest level of education completed by your parents

10) Do any of your parents work in a healthcare field

11) Do any of your relatives work in a healthcare field

12) In your household, which language is most spoken

13) Have you heard of the Zika virus

14) Where have you been getting your information about Zika from [multiple choice]

15) Are you concerned you might get Zika

16) How do you get Zika [multiple choice]

17) How do you prevent getting Zika [multiple choice]

18) What are the side effects of Zika [multiple choice]

19) What are the signs and symptoms of Zika [multiple choice]

20) Why should women who are pregnant or planning pregnancy know about Zika [multiple choice]

21) Does it affect women if they're not pregnant

22) Should you avoid areas that are infected with Zika

23) Is there a cure for Zika

24) What would you do if you found out you had been exposed to Zika [multiple choice]

25) Do you think your doctor can treat Zika

26) Have you taken any action to prevent yourself/your family from getting Zika

27) Do you think it's important you know more about Zika

28) How much time would you spend to learn more about Zika [multiple choice]

29) What do you consider a trustworthy source of information [multiple choice]

\subsection{Statistics}

Summary statistics were obtained for quantitative data: the population size $(N)$, sample size $(n)$, mean, standard deviation $(S D)$, median, minimum, and maxi- 
mum. All were assessed using Microsoft Excel.

\section{Results}

\subsection{Demographics and Baseline Characteristics}

A total of 185 students signed the electronic assent form. Of the students who assented to participation, 157 qualified for inclusion, because they had heard of Zika prior to this study. A total of 151 students completed all of the questions. The mean age of qualified students was $16.4 \pm 1.1$ years. The majority of the students were female (55\%), white (76\%), and non-Hispanic (88\%). Most students surveyed resided in the Northeast region of the United States (65\%). Out of 157 students, $74(47 \%)$ were in the $11^{\text {th }}$ grade. Most of the parents of those surveyed (91\%) are believed to have completed a college degree; $30 \%$ of the qualified participants had parents in healthcare; $51 \%$ had relatives in healthcare.

\subsection{Zika Knowledge}

Zika virus knowledge was limited amongst high school students (Figure 2). When asked how Zika is spread, only $38 \%$ of students correctly identified all possible transmission mechanisms. When asked "How do you prevent getting Zika?", 28\% of students were able to correctly answer all possible prevention mechanisms. Participants were also asked about the side effects of Zika, as well as about the symptoms and signs of the virus. Although $87 \%$ of students knew that serious birth defects and pregnancy problems were a side effect of the Zika virus, only 50\% were aware that Zika may cause brain damage. Knowledge was even more limited regarding the signs and symptoms of the disease. Only $4 \%$ of qualified students identified all of the four signs and symptoms-headache, rash, fever and joint and muscle pain-correctly without selecting one of the three incorrect choices. However, the majority (63\%) of qualified students were aware that Zika effects women regardless of pregnancy status. However, the majority of qualified respondents (63\%) were aware that Zika affects women regardless of pregnancy status (Figure 3 ).

The two sources that study participants considered most trustworthy were school and the internet, $76 \%$ and $72 \%$, respectively. They moderately trusted information from family (48\%) and television (46\%). They generally did not trust information from friends (16\%).

\subsection{Zika Attitudes}

While the majority of respondents expressed a desire to be further educated about the Zika virus, students were not concerned with contracting it. Qualified students acknowledged that they should avoid areas associated with Zika, with $81 \%$ indication. Furthermore, $76 \%$ of the students answered that they thought it is important to know more about Zika virus. Three-quarters of those surveyed said that they would spend some time to learn more about Zika. Notwithstanding these attitudes towards the importance of receiving education on the virus, 


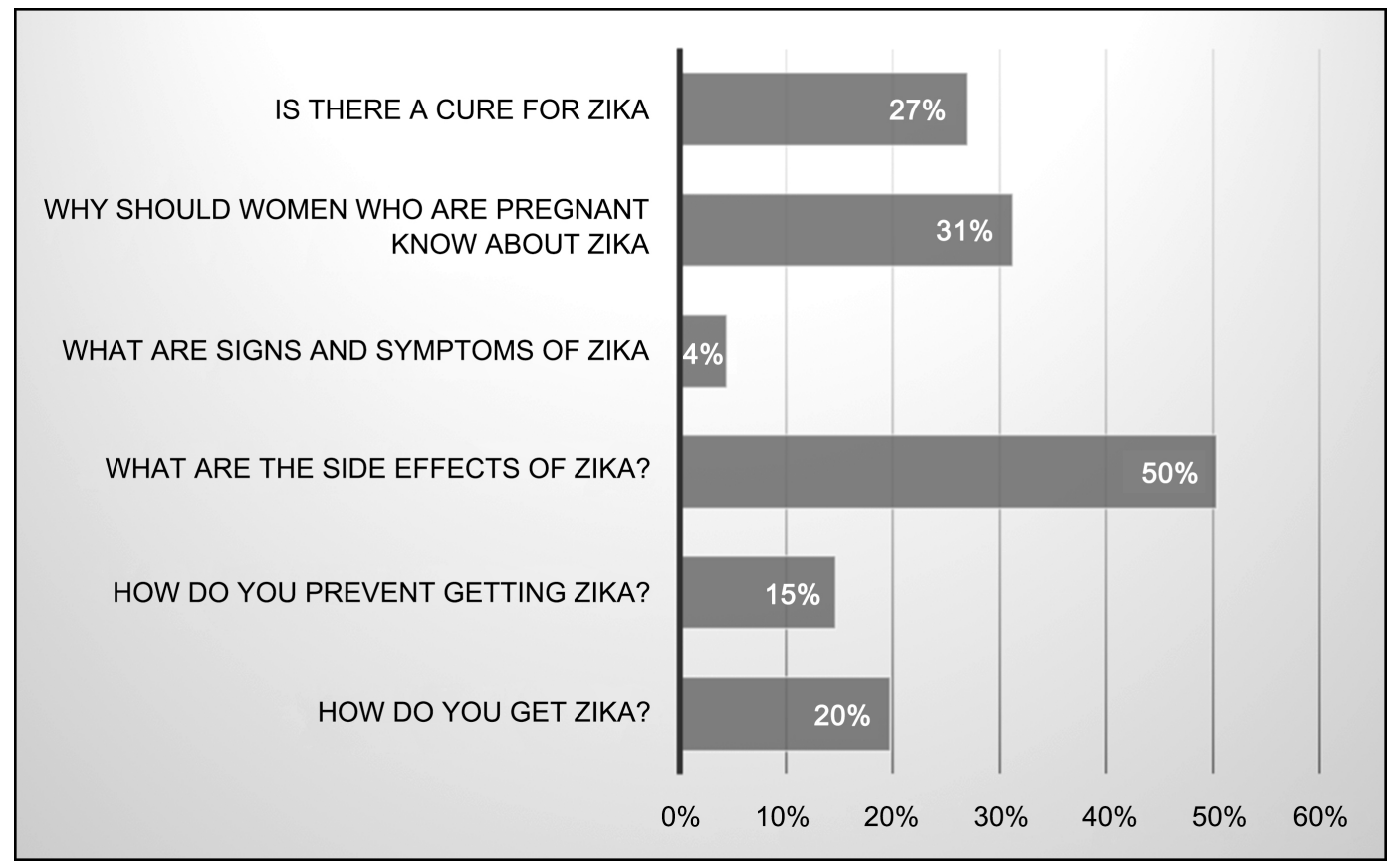

Figure 2. General knowledge of Zika is limited in high-school students. Knowledge of Zika is depicted by the percentage of qualified students surveyed who selected all correct answers for each question. Questions were multiple choice with one or more answers permitted.

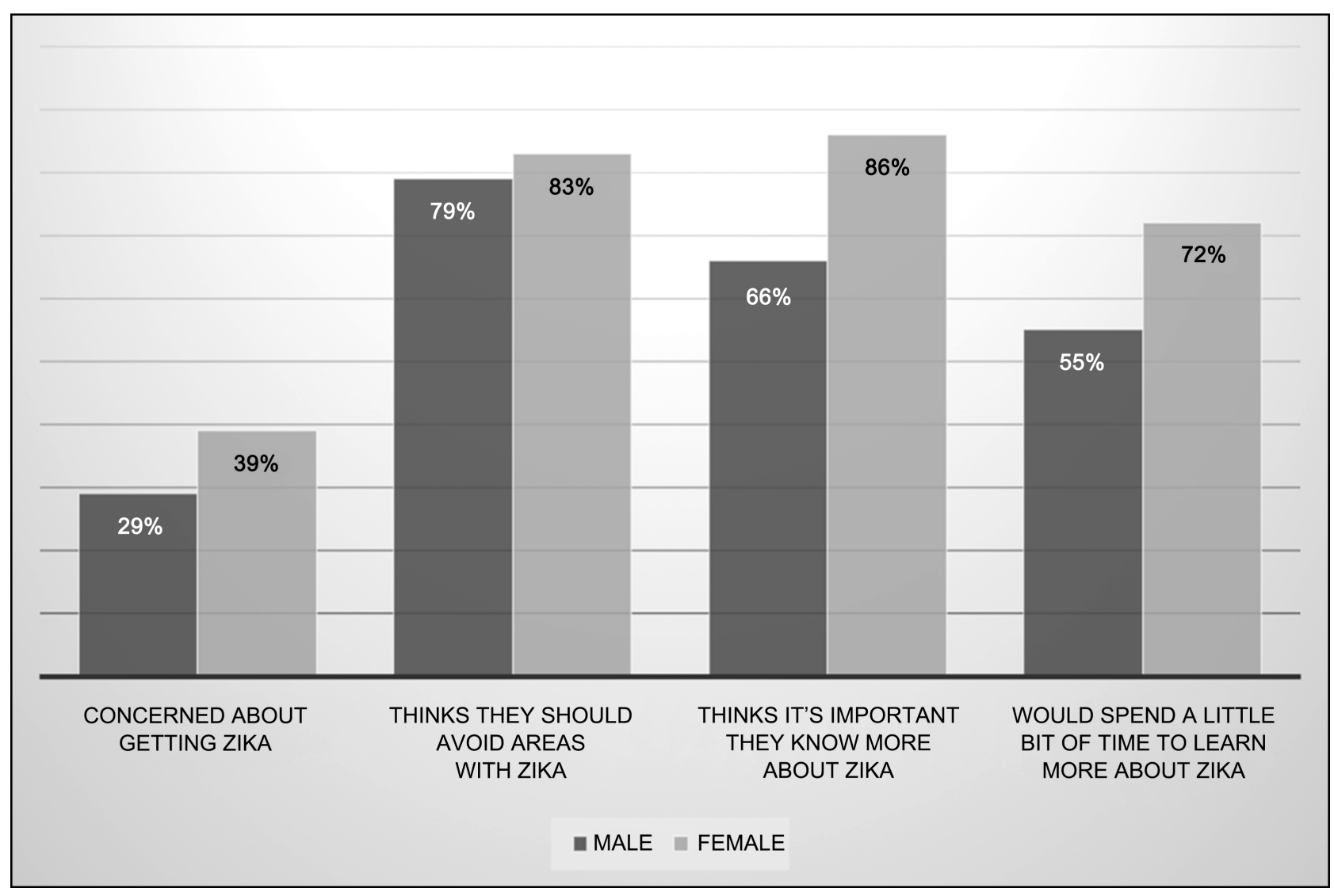

Figure 3. Female respondents tended toward being more concerned than males with the Zika virus. Attitudes towards Zika are shown as a percentage of qualified respondents who indicated each answer. Differences were not statistically different. 
only $33 \%$ signaled that they were at all concerned with getting Zika. There was a trend suggesting that female high-school students are more concerned than are males, but the difference was not statistically significant (chi-square test, $p=$ 0.23 ) (Figure 3).

\subsection{Zika Practices}

Eighty-nine percent of respondents indicated that they would to talk to a doctor or parents if they discovered that they had been exposed to Zika, and only $4 \%$ responded that they would do nothing (Figure 4). However, they appear unsure of what can be done about Zika. More than $1 / 3^{\text {rd }}(42 \%)$ responded "I am not sure" when asked if their physician could treat Zika. Just $18 \%$ of students reported that they had taken any measures to prevent themselves or their relatives from Zika exposure.

\section{Discussion}

Since there is no cure or vaccine for Zika, we consider the findings of this survey to be relevant for future emerging epidemics in that they may impact behavior with the intention of preventing and treating a vector-borne disease. [9] To be sure, Zika is a unique virus in that it is both transmitted by mosquito vector as well as being detectable in the blood and semen of infected individuals for weeks or months following infection. [10] It is important to ascertain if and how information about the nature, prevention, and treatment of such a novel virus is disseminated in the population, particularly young people. [11] For example, a study of 613 undergraduate college students from a large public university in Virginia found that few felt at risk for the disease (12.1\%), but did recognize that it was a risk in specific parts of the world to pregnant women (83\%), while $44 \%$

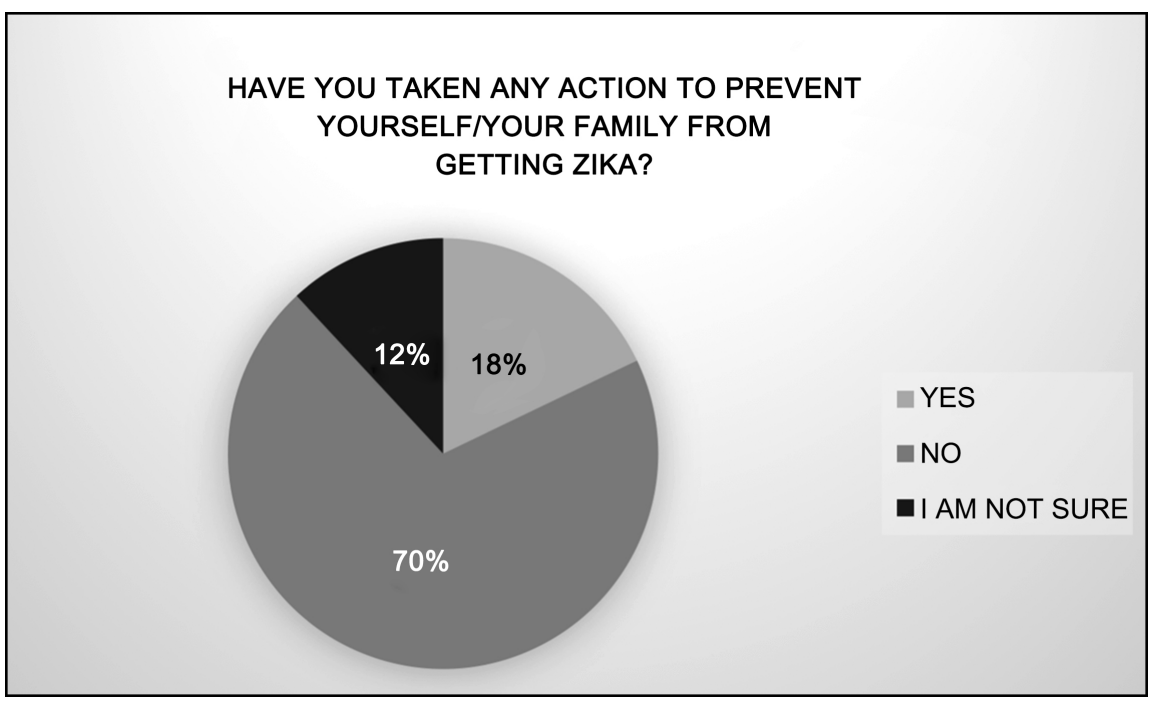

Figure 4. Students surveyed have taken little action to protect themselves from Zika. The percentage of qualified students surveyed who indicated whether or not they had taken any action to prevent themselves or their family from getting Zika is shown. 
said they did not know where to get accurate information about Zika [11]. Knowledge gaps have been identified by public health officials as an important need for improvement with respect to the Zika virus and other viruses that might pose a risk in the future [12].

Zika poses a particular and very serious risk to pregnant women and those who wish or plan to become pregnant. It may be that students in our survey were less concerned about this risk than a different population might have been. The possibility of sexual transmission of a mosquito-borne virus is unusual, [13] and it is important to note that the high-school respondents were aware that such transmission was possible with Zika.

The importance of this survey demonstrates that high-school students are largely aware of public health threats, novel epidemics, and that they seek accurate information about these conditions, even to the point of taking steps to protect themselves. A key finding of our study is that these students relied mainly on their academic institutions and online sources to get reliable information about Zika. This suggests that public health officials can effectively use social media and other internet sites to post accurate, timely, and actionable information about future disease outbreaks.

In light of the COVID-19 pandemic, this survey suggests that high-school students are interested in public health topics and that educational interventions targeted specifically to this age group might find resonance.

Our study was a survey of high-school students at four different schools in different parts of the country. Most respondents were from the Northeast, a region that did not have Zika outbreaks and is at less risk for mosquito-borne diseases than Southern regions. There was no control group and students were limited as to what and how they could respond-there were multiple-choice questions only with only two write-in opportunities. We excluded students from the results if they did not know about Zika, meaning our population had knowledge of Zika that may not be representative of what most students know.

This survey of high-school students yielded results that are quite similar to the results of surveys of Philippine public secondary-school teachers (good knowledge about vector transmission, but relatively poor knowledge on other aspects, plus a low level of perceived susceptibility and severity) [14], U.S. physician-assistant students, [15] and Malaysian community pharmacists [16].

\section{Conclusion}

High-school students were aware and knowledgeable about the Zika virus without being unduly alarmed or concerned about it. The emergence of the Zika virus has not caused students to take any unusual steps to prevent the disease, but the majority said they would tell parents and/or a physician if they thought they might have been exposed. Students got most of their information from school and online sources they deemed reliable. The results suggest that high-school students are willing to learn about the danger and modify their behavior appro- 
priately when new emerging diseases are reported. It is now incumbent on the older generations to make accurate information available.

\section{Acknowledgements}

The authors thank Scott Delong for proofreading.

\section{Conflicts of Interest}

The authors declare no conflicts of interest regarding the publication of this paper.

\section{References}

[1] Sharma, V., et al. (2020) Zika Virus: An Emerging Challenge to Public Health Worldwide. Canadian Journal of Microbiology, 66, 87-98. https://doi.org/10.1139/cjm-2019-0331

[2] Dick, G., Kitchen, S. and Haddow, A. (1952) Zika Virus (I). Isolations and Serological Specficity. Transactions of the Royal Society of Tropical Medicine and Hygiene, 46, 509-520. https://doi.org/10.1016/0035-9203(52)90042-4

[3] MacNamara, F. (1954) Zika Virus: A Report on Three Cases of Human Infection during an Epidemic of Jaundice in Nigeria. Transactions of the Royal Society of Tropical Medicine and Hygiene, 48, 139-145. https://doi.org/10.1016/0035-9203(54)90006-1

[4] CDC (2019) Zika in the US. https://www.cdc.gov/zika/geo/index.html

[5] Squiers, L., et al. (2019) Zika and Travel in the News: A Content Analysis of US News Stories during the Outbreak in 2016-2017. Public Health, 168, 164-167. https://doi.org/10.1016/j.puhe.2018.12.009

[6] Darrow, W., Bhatt, C., Rene, C. and Thomas, L. (2018) Zika Virus Awareness and Prevention Practices among University Students in Miami: Fall 2016. Health Education \& Behavior, 45, 967-976. https://doi.org/10.1177/1090198118760687

[7] Seltzer, E.K., Horst-Martz, E., Lu, M. and Merchant, R.M. (2017) Public Sentiment and Discourse about Zika Virus on Instagram. Public Health, 150, 170-175. https://doi.org/10.1016/j.puhe.2017.07.015

[8] Pielnaa, P., et al. (2020) Zika Virus-Spread, Epidemiology, Genome, Transmission Cycle, Clinical Manifestation, Associated Challenges, Vaccine and Antiviral Drug Development. Virology, 543, 34-42. https://doi.org/10.1016/j.virol.2020.01.015

[9] Tambo, E., et al. (2017) Ethical, Legal and Societal Considerations on Zika Virus Epidemics Complications in Scaling-Up Prevention and Control Strategies. Philosophy, Ethics, and Humanities in Medicine, 12, Article No. 3. https://doi.org/10.1186/s13010-017-0046-8

[10] Medina, F.A., et al. (2019) Duration of the Presence of Infectious Zika Virus in Semen and Serum. The Journal of Infectious Diseases, 219, 31-40.

[11] Plaster, A.N., Painter, J.E., Tjersland, D.H. and Jacobsen, K.H. (2018) University Students' Knowledge, Attitudes, and Sources of Information about Zika Virus. Journal of Community Health, 43, 647-655. https://doi.org/10.1007/s10900-017-0463-Z

[12] Tambo, E., et al. (2017) Addressing Knowledge Gaps in Molecular, Sero-Surveillance and Monitoring Approaches on Zika Epidemics and other Arbovirus Co-Infections: A Structured Review. Parasite Epidemiology and Control, 2, 50-60. 
https://doi.org/10.1016/j.parepi.2017.01.001

[13] Joob, B. and Wiwanitkit, V. (2019) Female-to-Male Sexual Transmssion of Zika Virus Infection. Family Medicine \& Community Health, 7, e000183.

https://doi.org/10.1136/fmch-2019-000183

[14] Gregorio Jr., E.R., et al. (2019) Knowledge, Attitudes, and Practices of Public Secondary School Teachers on Zika Virus Disease: A basis for the Development of Evidence-Based Zika Educational Materials for Schools in the Philippines. PLoS ONE, 14, e0214515. https://doi.org/10.1371/journal.pone.0214515

[15] Wishner, C., et al. (2020) Physician Assistant Students' Knowledge of Zika Virus: A Pilot Study. Infectious Diseases. Research and Treatment, 13, 1-11.

https://doi.org/10.1177/1178633720909158

[16] Lim, K.Y. and Tham, H.W. (2020) Knowledge, Awareness, and Perception of Community Pharmacists to Zika Virus Infection in Klang Valley, Malaysia. Health Services Insights, 13, 1-11. https://doi.org/10.1177/1178632920921425 